\title{
Dependence of E-H transition in argon ICP discharges for treatment of organic molecules
}

\author{
Carlos Eduardo Farias ${ }^{1}$, Euclides Alexandre Bernardelli ${ }^{1}$, \\ Paulo César Borges ${ }^{1}$, Marcio Mafra ${ }^{1}$
}

\author{
${ }^{1}$ Laboratório de plasma - PPGEM/DAMEC/UTFPR CEP 81280-350, Curitiba, PR \\ e-mail: mafra@utfpr.edu.br, cefarias@utfpr.edu.br, ebernardelli@utfpr.edu.br, pborges@utfpr.edu.br
}

\begin{abstract}
Plasma surface cleaning is an alternative process that aims at the fully removal of organic contaminants on several kinds of materials. Despite its advantages, there are still lacks on the comprehension of the complex relations between plasma-generated species and organic molecules during plasma cleaning. In the present work, a linear alkane (hexatriacontane $-\mathrm{C}_{36} \mathrm{H}_{74}$ ), used as a contaminant model, was exposed to an Argon radiofrequency (RF) inductively coupled plasma (ICP). The by-products from degradation were monitored by optical emission spectroscopy (OES) and residual gas analysis (RGA), to identify the influence of sample positioning on $\mathrm{E}$ and $\mathrm{H}$ discharge modes regions. The exposition to $\mathrm{H}$-mode discharge resulted in more intense and profuse emissions of $\mathrm{C}-\mathrm{H}$ and $\mathrm{C}_{2}$ systems. RGA results show similar byproducts from degradation in both modes; however, the intensity from treatment in H-mode is largely greater. It was also observed that plasma etching in H-mode is enough to melt the sample, while E-type discharge leaves the surface of the sample apparently unchanged.
\end{abstract}

Keywords: ICP; RF Plasma; E-H transition; OES; RGA.

\section{INTRODUCTION}

There are several ways to treat the surface of materials to modify its properties [1]. Plasma technologies comprehend a wide range of treatments, from coatings [2] and nitriding of steels [3] to modification of biomaterials [4]. These treatments have interesting characteristics, such as to be a dry and environmentfriendly treatment medium, with ability to work from very low to very high pressures and temperatures, normally with low resource consumption [5,6]. However, plasma treatments are sensitive to the mode of its generation, operation conditions and to the geometry and dimensions of reactors, which can considerably change treatments efficiency and results.

Inductively coupled radiofrequency reactors can produce E-H transitions, that are different modes of plasma generation. In an ICP reactor, plasma is initially generated in a capacitive way by a static electric field between the segments of the coil, called as E-mode. At higher powers, an inductive mode becomes relevant, generating plasma due to an electromagnetic field from the same coil, called as H-mode. Often, these discharges are generated by E-mode and the transition can occur by increasing the applied power, which is visible by a sudden increase on discharge brightness size and density [7-9]. Several studies already evaluated the changes that occur in plasma properties during this transition and some of the most relevant results are as follows: E-mode has an electron density generally close to $10^{9} \mathrm{~cm}^{-3}$, while $\mathrm{H}$-mode ranges from $10^{10}$ to $10^{11} \mathrm{~cm}^{-3}$ at the same applied power $[8,10,11]$; the plasma potential is reduced at the H-mode even with the increase of applied power $[12,13]$; the EEDF changes to a more Maxwellian electron distribution at the Hmode [9, 10, 14]; electron temperature is reduced at H-mode, while gas temperature is increased [13-15]; electron-electron collision frequency is greatly increased [12]; after the H-mode is initiated, it can be sustained even at lower powers [12, 16]; finally, both $\mathrm{E}$ and $\mathrm{H}$ modes can coexist inside the reactor [9].

However, up to now, there was only one study about the treatment of organic molecules that could be related to this specific transition in ICP discharges. THIRY et al. [17] studied different treatment behaviours of propanethiol (in gas phase) to material deposition and growth, in both ICP discharges modes. The results showed that higher discharge temperatures and electron densities leaded to higher fragmentation of propanethiol.

The present work is a complement of previous studies from MAFRA et al. [18], BERNARDELLI et 
al.[19], FARIAS et al. [20] where the mechanisms of plasma degradation of organic molecules are studied. The set of experiments here presented aims to gain a better understanding in this issue, by investigating the differences on degradation of hexatriacontane in $\mathrm{E}$ or $\mathrm{H}$ modes, monitoring the by-products of the treatments.

\section{MATERIALS}

The experimental setup is shown in Figure 1 and in the following description. The plasma reactor consists of a quartz tube with $36 \mathrm{~mm}$ inner diameter and $1000 \mathrm{~mm}$ length. The plasma is generated by a 9 turns copper coil, connected to a $13.56 \mathrm{MHz}$ radiofrequency power source Tokyo Hi-Power, RF-300 model, and a matching box (MB-300). All experiments here presented were carried out at the fixed power of $150 \mathrm{~W}$ (400 $\mathrm{V}$ peak-to-peak). The treatments were performed in 99,999\% pure Argon, flowing at $300 \mathrm{sccm}$, at pressure of 1 Torr.

In this configuration and settings, H-mode is centered close to the last turn of the coil, with a size of about $10 \mathrm{~cm}$ of tube length. Therefore, in this setup the H-mode plasma can be easily changed by moving the coil, while the sample was at a fixed position in relation to the optical system.

The sample holder was a glass plate, with dimensions of $76 \times 25 \times 1 \mathrm{~mm}$. The material chosen as contaminant model was hexatriacontane $\left(\mathrm{C}_{36} \mathrm{H}_{74}, 95 \%\right.$ pure $)$, from Fluka ${ }^{\circledR}$, cold pressed in a shape of cylindrical wafer with $16 \mathrm{~mm}$ of diameter and $1 \mathrm{~mm}$ height (approximately $200 \mathrm{mg}$ ).

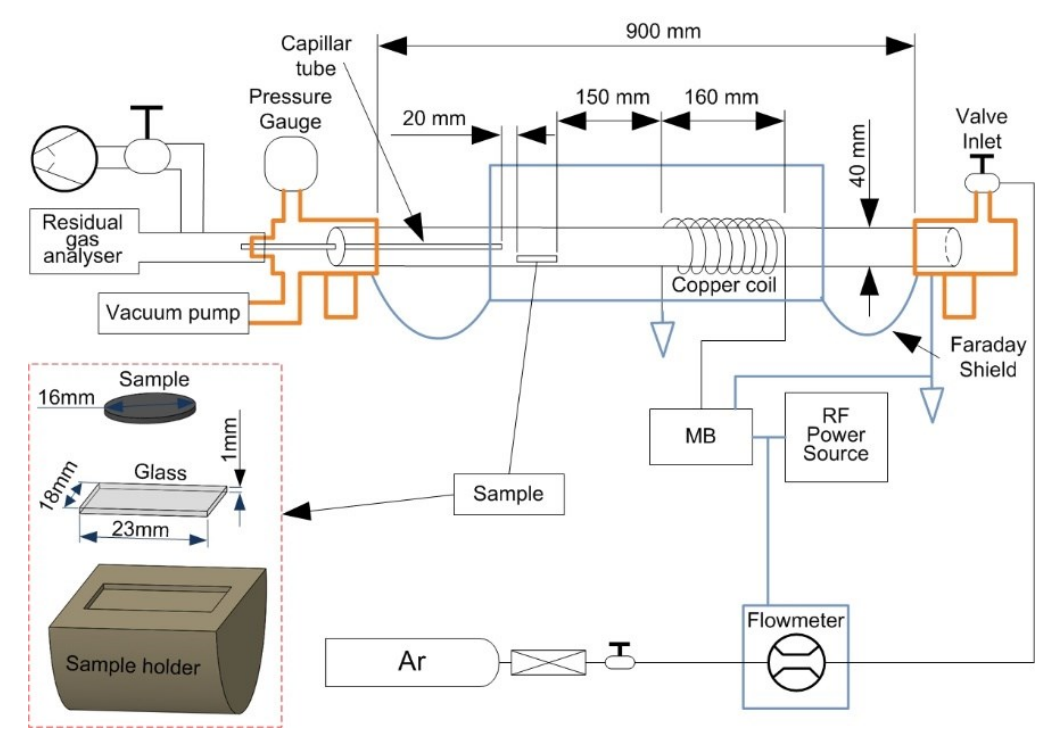

Figure 1: Experimental setup.

The by-products characterization was made by optical emission spectroscopy (OES) and residual gas mass spectrometry (RGA). OES used a Horiba optical spectrometer, iHR 550 model, collecting emissions in the range from 200 to $1200 \mathrm{~nm}$, and data averaged from 3 scans. This system, with a 1200 grid, have a spectral resolution of 0,015nm FWHM. RGA analysis used a Residual Gas Analyser Accu-quad RF-2910 model with range from 1 to $100 \mathrm{~m} / \mathrm{Z}$ with precision of $1 \mathrm{~m} / \mathrm{Z}$ with internal pressure of 8,5E-4 Torr.

In both modes $(\mathrm{E}$ and $\mathrm{H})$, over the tube length, there are visible modifications of Argon plasma color in relation to the sample position, as can be seen in Figure 2.

In this system, normally Argon discharge has a pink color characteristic and any deviations from this tonality can be indications of leaks or gas contamination, as can be seen in the picture without sample. When organic materials are present, as seen in the picture with sample, it visually changes discharge appearance to a blue color, even in small amounts as contaminations from reactor walls. 


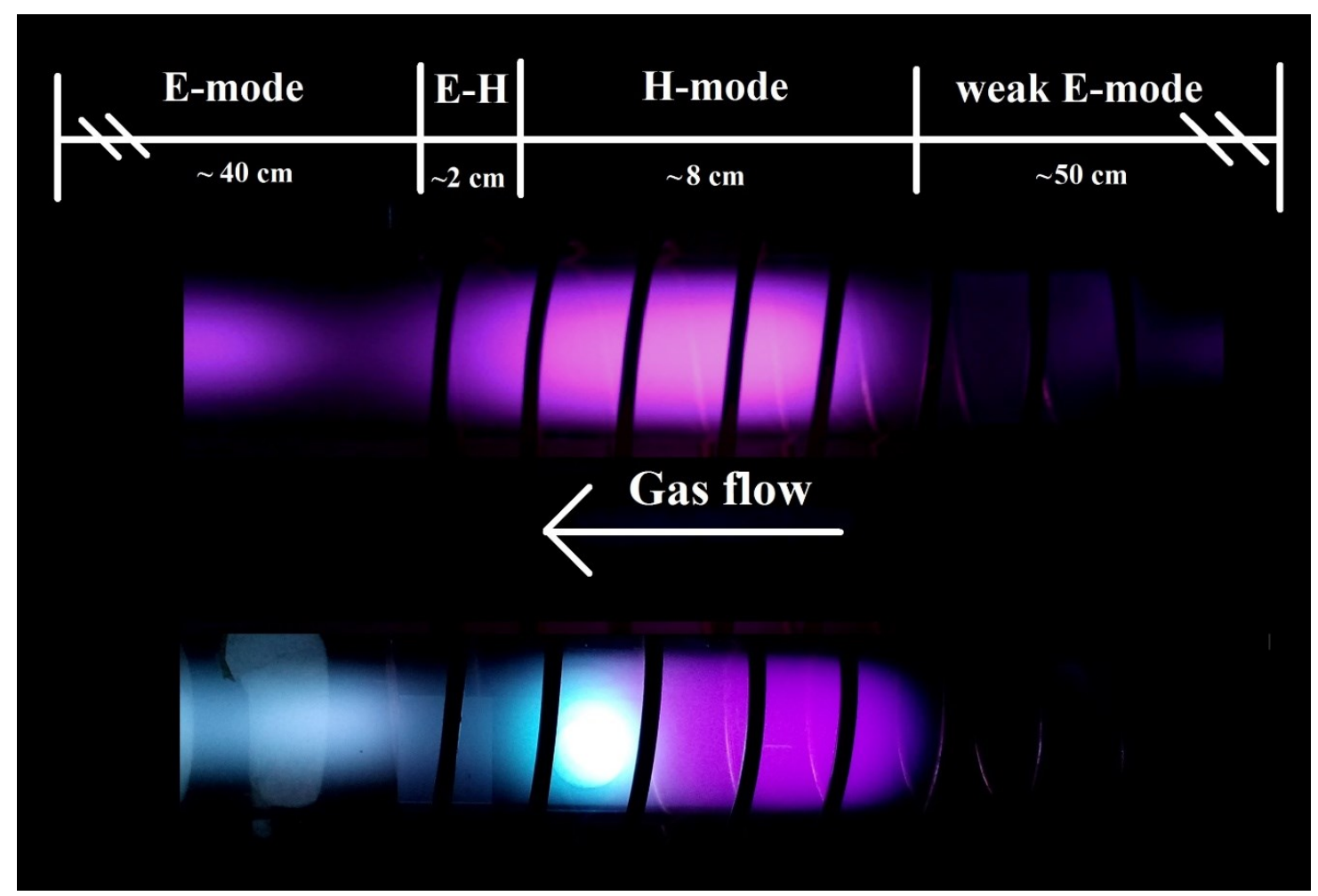

Figure 2: Photography of the sample in the discharge.

Other interesting observation is related to H-mode in Figure 2. Probably due to plasma perturbations related to sample holder, $\mathrm{H}$-mode has difficulty in existing close to sample holder, lasting no more than 20 $\mathrm{mm}$ after that. Due to this condition, sample position in sample holder is pushed closer to the border to make the treatment possible.

\section{RESULTS}

Figure 3 shows the spectra from the two interest regions $(\mathrm{E}$ and $\mathrm{H})$ of the plasma, without hexatriacontane sample. These results show mostly peaks of $\mathrm{Ar}^{+}$and low intensity residual peaks from $\mathrm{H}_{\alpha}$ and $\mathrm{O}$, which are related to residual water or gas impurities.

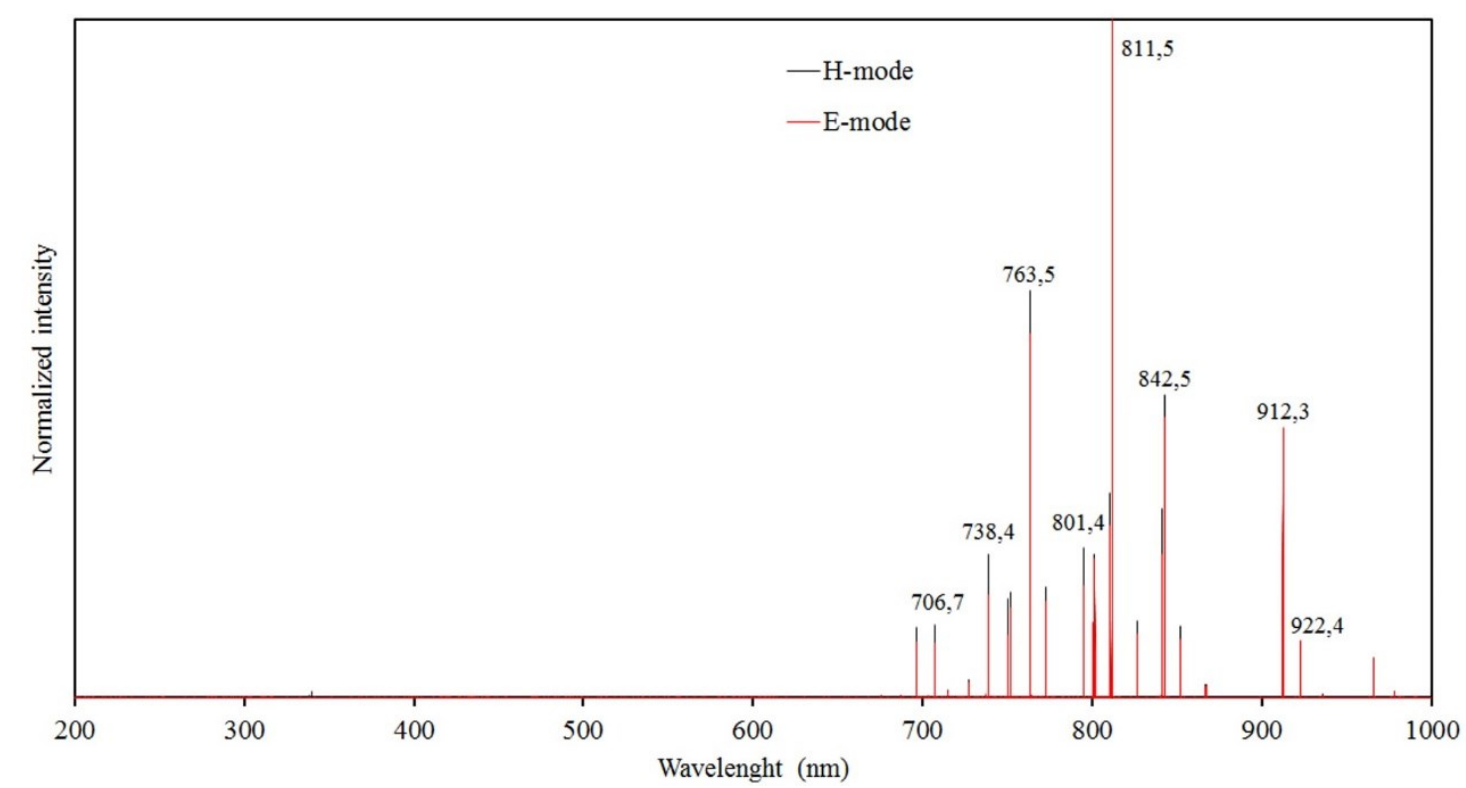

Figure 3: OES analysis showing Ar transition lines in both modes without sample. Both acquisitions were made with 0,4 seconds of exposition. 
Figure 4 shows the comparison of both modes in the presence of the organic sample. In this case, OES analysis is focused on most changed spectroscopic regions, concerning to emissions of byproducts of degradation. Since E-mode discharge presents less intense emissions than H-mode, the acquisition time to Emode data was higher than to H-mode. As a consequence, some Ar I peaks can be higher in this first one, even after normalization of data.

In Figure 4, four regions were selected. First, one of most intense C-H emission bond at $430 \mathrm{~nm}$ (called $430 \mathrm{~nm}$ System) related to $\mathrm{A}^{2} \Delta-\mathrm{X}^{2} \Pi$ transition is presented in Figure 4.a in H-mode, while on Emode only few peaks from this system are identified. This band is degraded to violet and consist of narrow doublets with a band head at $431,4 \mathrm{~nm}$, meaning an odd number of electron in the molecule. Other $\mathrm{C}-\mathrm{H}$ systems at $390 \mathrm{~nm}$ and $314 \mathrm{~nm}$ were also detected (specially on H-mode), but with minimal intensity. In Figure $4 \mathrm{~b}-\mathrm{d}$, those other regions are selected on most characteristics of C-C emission, called Swan system, and related to $\mathrm{A}^{3} \Pi_{\mathrm{g}}-\mathrm{X}^{3} \Pi_{\mathrm{u}}$ transition [21].

The most intense Swan system emission (Figure 4.b) is a singlet at 516,5 nm, degraded to violet, but it also produces many other similar peaks in $545-565 \mathrm{~nm}$ and $460-475 \mathrm{~nm}$ regions (Figures $4 \mathrm{c}-\mathrm{d}$ ), characteristics of many relaxing mechanisms and states of organic molecules [21]. At these ranges, only Hmode produced significant emissions, which can be related to two sources. Firstly, H-mode is very bright and intense, thus contributing to an increase of molecular fragments excitement. Secondly, the heating produced in H-mode favored degradation and volatilization of hydrocarbon species to plasma. However, as will be observable in RGA analysis, both conditions lead to degradation of hexatriacontane in smaller organic fragments, despite the difference of intensities.

Nevertheless, as previous works [22-24] have already stated, those degradation processes in a plasma environment are very temperature sensitive. In E-mode, even after long treatment times, sample surface remained almost unmodified. On the other hand, in H-mode, sample melted in less than 3 minutes of exposition, showing a remarkable heating and degradation capacity. It was observed that a very long time in $\mathrm{H}$-mode will lead to an almost elimination of sample. It is remarkable because, in oxygen containing plasmas, the degradation processes at higher temperatures are accompanied of oxygen functionalization of the organic sample, leading to production of resistant products [25].

a)

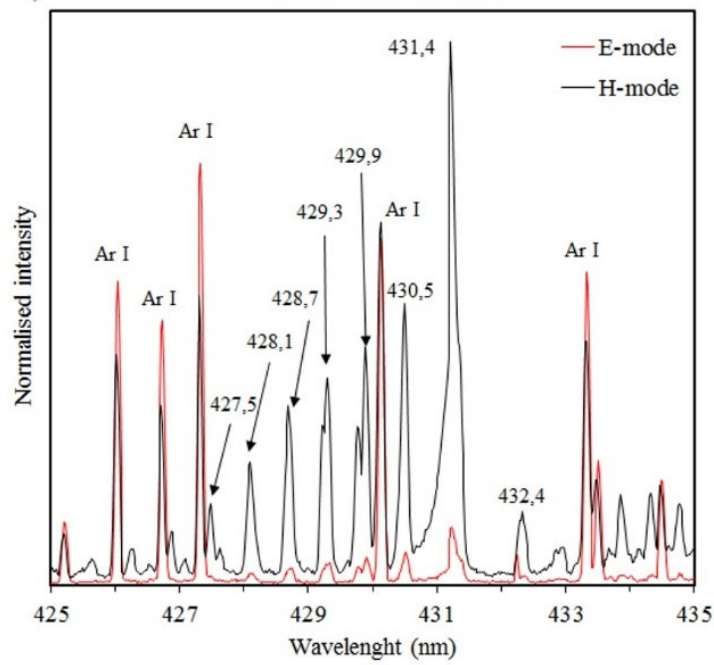

b) C-C - Swan System $(460-475 \mathrm{~nm})$

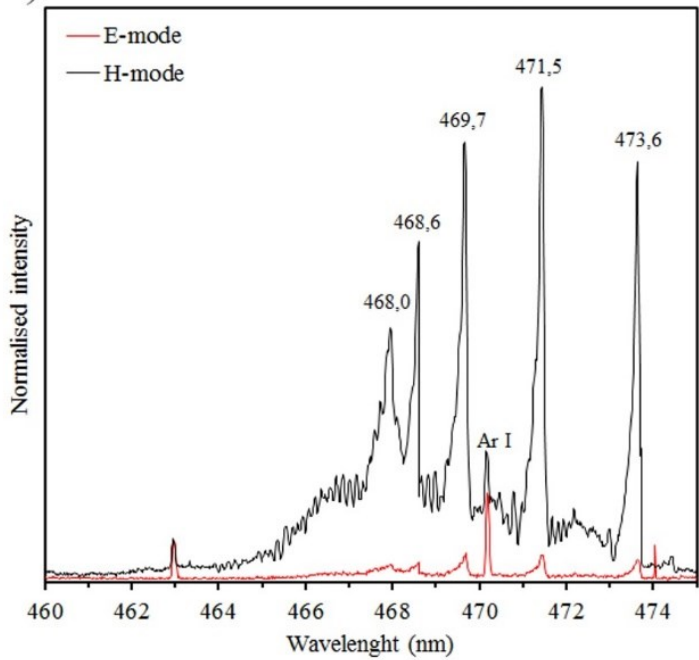


c)

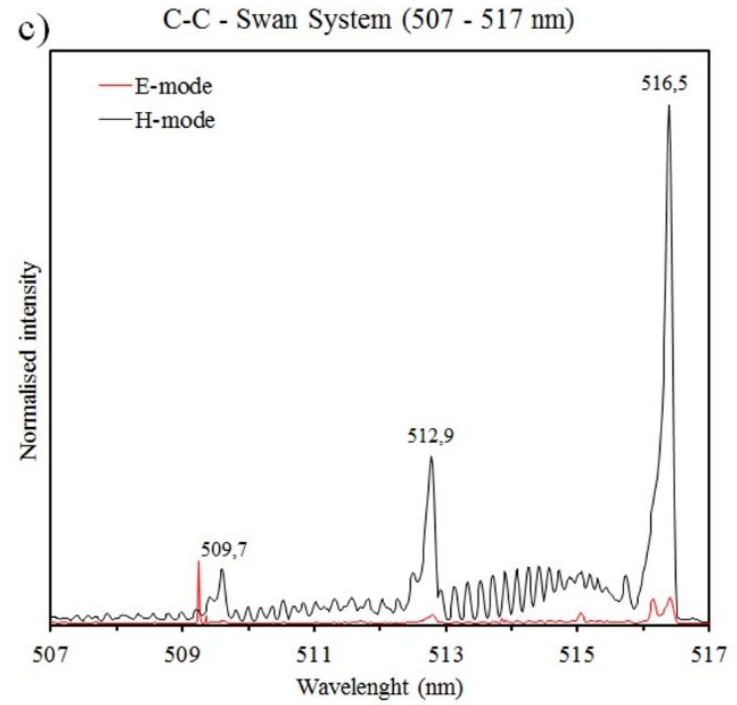

d) C-C - Swan System $(545-565 \mathrm{~nm})$

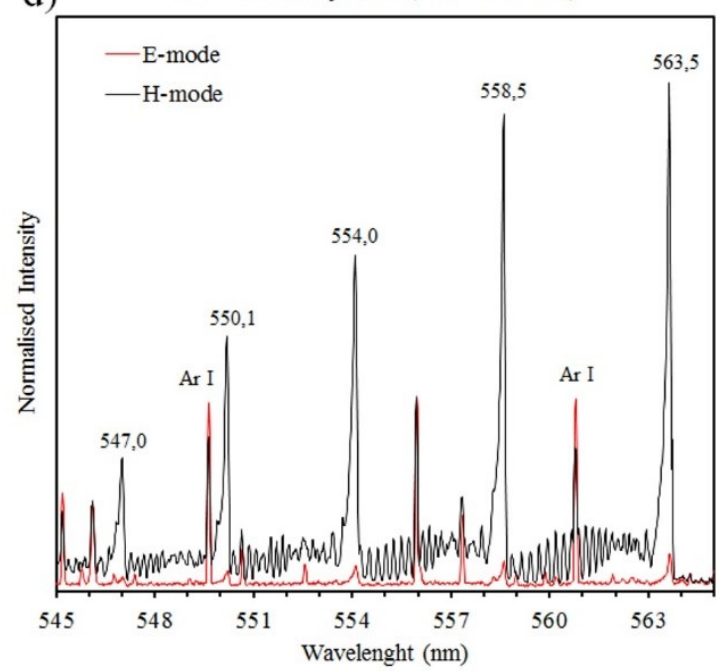

Figure 4: OES analysis from observable ranges. H-mode used 5 seconds and E-mode used 30 seconds of camera acquisition.

H-mode is known to have a higher ion temperature than E-mode $[12,13,15]$ and this is a considerable source of heating in plasmas. Additionally, the higher electron density and electron energy distribution function (EEDF) at lower values, found in H-mode, can also lead to dissociative electron attachment (DEA) on sample surface, which could also increase heating by bond dissociation [26].

RGA analysis is also very dependent on sample temperature and, since it was not possible to control this variable in this system, the results from RGA analysis were not able to separate what was E or H-mode purely related and what was temperature related. Figure 5 shows RGA data from E-mode plasma treatment after 20 minutes of heating and from H-mode before sample melting (first 5 minutes). 

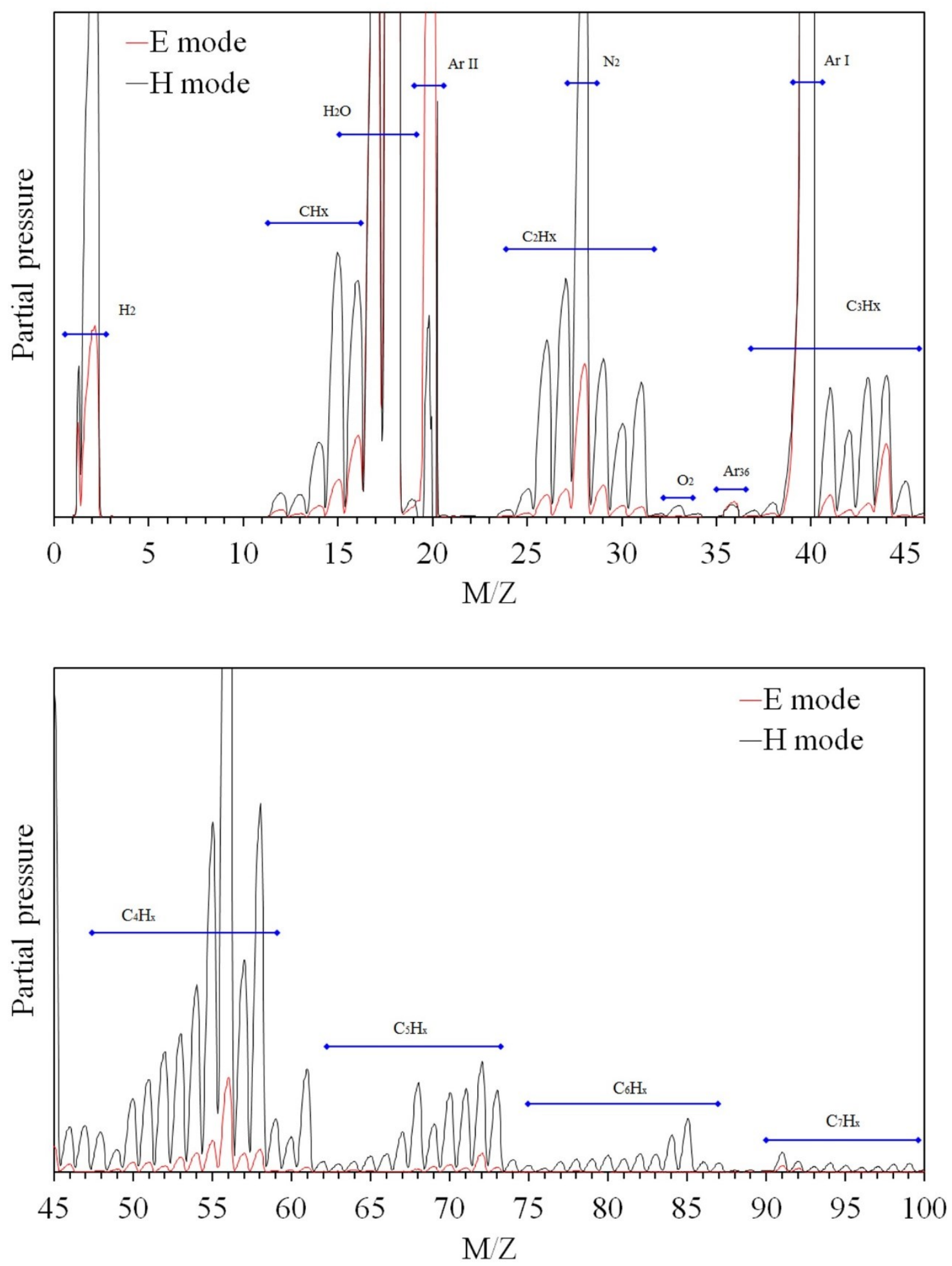

Figure 5: RGA analysis in $\mathrm{E}$ and $\mathrm{H}$ modes with identified molecules marked. Plot (a) from 0 to $46 \mathrm{~m} / \mathrm{Z}$ is zoomed to main interest species and plot (b) from 45 to $100 \mathrm{~m} / \mathrm{Z}$ is very zoomed (check $\mathrm{m} / \mathrm{Z} 46$ on both) showing residual carbonic species.

In RGA analysis, in Figure 5.a, most present species are related to Argon first (m/z 40 (main) and $38 / 36$ from isotopes) and second ( $\mathrm{m} / \mathrm{z} 20)$ ionizations and residual water (m/z 18, 17, 16 and 19 (weak)) from the inside of spectrometer. Due to some minimal leaking, hard to eliminate on vacuum systems and gas contamination, some partial pressure from $\mathrm{N}_{2}$ (m/z 28 and 29), $\mathrm{CO}\left(\mathrm{m} / \mathrm{z} 28,29\right.$ and 30) and $\mathrm{CO}_{2}(\mathrm{~m} / \mathrm{z} 44)$ is also present in the RGA analysis. In this system, oxygen $(\mathrm{m} / \mathrm{z} 32)$ presence was very minimal, probably 
created by water dissociation and leaking. Part of this oxygen could also react with sample, increasing the presence of $\mathrm{CO}$ and $\mathrm{CO}_{2}$.

Comparing both modes in these molecules, there is no visible changes, except for water. Since Hmode leads to higher temperature on surfaces, it would increase degassing of water from reactor walls and thus increasing the partial pressure of water.

Other point to take note in Figure 5.a is the peaks with $\mathrm{m} / \mathrm{z} 31$ and 45 . These ones are almost exclusively related to fragments of primary alcohols like methanol, ethanol and propanol. However, when considering gas (99,999\% pure argon) and sample (hexatriacontane have only $\mathrm{C}$ and $\mathrm{H}$ atoms) composition, it is not possible to obtain primary alcohol during plasma treatment. Later, it was verified that the intensity of $\mathrm{m} / \mathrm{z} 31$ and 45 were dependent of two variables, namely the presence of alkene fragments and water concentration. Inside RGA spectrometer, due to its low pressure and low gas flow from reactor to RGA, there is always a considerable amount of water degassing from system walls. With this combination of factors, plus an ionizing source (RGA filament), it is possible to combine the fragments of those molecules to form alcohol. OZEN et al. [27] and JIN et al. [28] observed this kind of reactions but in different environments.

Considering the fragments from hexatriacontane, RGA analysis show, in both modes, the presence of carbonic species from one to seven carbon atoms, especially in H-mode. The most intense peaks detected result from fragments having from one to three carbons. THIRY et al. [17] also found the same behavior on RGA analysis, with most carbonaceous compounds with 1-3 carbons. The higher molar mass fragments need more energetic sources to be produced, or more temperature to become volatile in the vacuum chamber. Therefore, the detection of heavy fragments is greater in H-mode than in E-mode.

The source of those fragments were specific chain breaking mechanisms that occur while treating an linear alkane with argon plasma, mostly $\beta$-scission [29], dissociative electron attachment (DEA) [30] and ion impact. All these cited chains breaking mechanisms are sample temperature dependents, and so they are more efficient in H-mode, leading to more fragments. From these results, it is evident that H-mode is more efficient to produce hydrocarbon fragments from hexatriacontane, inclusively the high molar mass fragments. Since the intensity of these emissions are temperature dependent, it is not possible, at this moment, to state that this higher intensity in $\mathrm{H}$-mode is exclusively related to mode properties, but most probably a combination of temperature and higher reactivity.

\section{CONCLUSIONS}

In this paper it was possible to verify the higher degradation capacity of hydrocarbon molecules in H-mode of ICP-RF discharges. This H-mode of plasma generation is more intense and showed more reactivity related to degradations process for a non-oxidative gas, as Argon. OES and RGA analysis showed a relationship about the higher capacity of $\mathrm{H}$-mode in degradation of hexatriacontane, since the higher production of small hydrocarbon fragments observed in RGA analysis of $\mathrm{H}$-mode, also produced intense $\mathrm{C}-\mathrm{H}$ and $\mathrm{C}-\mathrm{C}$ emissions on OES. On the other hand, E-mode was able to produce detectable hydrocarbons fragments in RGA, but was not intense enough to excite a sufficient number of molecules to be detectable in OES analysis. Later researches on this topic will be made with additions of reactive gases.

\section{ACKNOWLEDGEMENT}

Authors kindly acknowledge the support given by Brazilian agencies of technological and scientific research: Fundação Araucária (FAPPR) proj. 25288-12/2011; CNPq projects 479593/2012-4 and 308798/2012-0; and CAPES by C. E. Farias grant.

\section{BIBLIOGRAPHY}

[1] REIDENBACH, F.R., ASM Handbook: Volume 5: Surface Engineering (Asm Handbook) (Asm Handbook, 10th ed. ASM International, 1994.

[2] ROCHE, J.D. La, GONZALEZ, J.M., PARRA, E.R., et al., "Structure and Properties of Titanium Doped Tungsten Disulfide Thin Films Produced via the Magnetron Co-Sputtering DC Technique", Matéria (Rio de Janeiro), v. 21, n. 2, pp. 461-469, Jun. 2016.

[3] ALMEIDA, E.A. dos S. de, COSTA, C.E. da, MILAN, J.C.G., "Study of the nitrided layer obtained by different nitriding methods", Matéria (Rio de Janeiro), v. 20, n. 2, pp. 460-465, Jun. 2015.

[4] NOMINÉ, A. V., MAFRA, M., FRACHE, G., et al., "Treatment of Glycine and Proline in Late Ar-O 2 Afterglow", Plasma Processes and Polymers, v. 12, n. 12, pp. 1459-1469, Dec. 2015. 
[5] ROTH, J.R., Industrial Plasma Engineering: Volume 2: Applications to Nonthermal Plasma Processing, Philadelphia, IOP Publishing Ltd, 2001.

[6] KELLER, J.H., "Novel radio-frequency induction plasma processing techniques", Journal of Vacuum Science \& Technology A: Vacuum, Surfaces, and Films, v. 11, n. 5, pp. 2487, Sep. 1993.

[7] KORTSHAGEN, U., GIBSON, N.D., LAWLER, J.E., "On the E - H mode transition in RF inductive discharges", Journal of Physics D: Applied Physics, v. 29, n. 5, pp. 1224-1236, May 1996.

[8] SEO, S.-H., CHUNG, C., CHANG, H.-Y. "Review of heating mechanism in inductively coupled plasma", Surface and Coatings Technology, v. 131, n. 1-3, pp. 1-11, Sep. 2000.

[9] ZHAO, S.-X., GAO, F., WANG, Y.-N., "Dynamic investigation of mode transition in inductively coupled plasma with a hybrid model", Journal of Physics D: Applied Physics, v. 42, n. 22, pp. 225203, Nov. 2009.

[10] LEE, Y.W., LEE, H.L., CHUNG, T.H. "E-H mode transition in low-pressure inductively coupled nitrogen-argon and oxygen-argon plasmas", Journal of Applied Physics, v. 109, n. 11, pp. 113302, Jun. 2011.

[11] WEGNER, T., KÜLLIG, C., MEICHSNER, J., "Mode transition and hysteresis in inductively coupled radio frequency argon discharge", Physics of Plasmas, v. 23, n. 2, pp. 23503, Feb. 2016.

[12] LEE, H.-C., LEE, J.-K., CHUNG, C.-W. "Evolution of the electron energy distribution and E-H mode transition in inductively coupled nitrogen plasma", Physics of Plasmas, v. 17, n. 3, pp. 33506, Mar. 2010.

[13] WEGNER, T., KÜLLIG, C., MEICHSNER, J., "On the E-H transition in inductively coupled radio frequency oxygen plasmas: I. Density and temperature of electrons, ground state and singlet metastable molecular oxygen", Plasma Sources Science and Technology, v. 26, n. 2, pp. 25006, Jan. 2017.

[14] LEE, H.-C., LEE, M.-H., CHUNG, C.-W., "Low energy electron heating and evolution of the electron energy distribution by diluted $\mathrm{O} 2$ in an inductive $\mathrm{Ar} / \mathrm{O} 2$ mixture discharge", Physics of Plasmas, v. 17, n. 1, pp. 13501, Jan. 2010.

[15] AMORIM, J., "High-density plasma mode of an inductively coupled radio frequency discharge", Journal of Vacuum Science \& Technology B: Microelectronics and Nanometer Structures, v. 9, n. 2, pp. 362, Mar. 1991.

[16] LEE, H.-C., CHUNG, C.-W., "Comparisons of the electrical characteristics by impedance matching conditions on the E-H and $\mathrm{H}-\mathrm{E}$ transition and the hysteresis of inductively coupled plasma", Thin Solid Films, v. 521, pp. 185-188, Oct. 2012.

[17] THIRY, D., BRITUN, N., KONSTANTINIDIS, S., et al., "Experimental and Theoretical Study of the Effect of the Inductive-to-Capacitive Transition in Propanethiol Plasma Polymer Chemistry", The Journal of Physical Chemistry C, v. 117, n. 19, pp. 9843-9851, May 2013.

[18] MAFRA, M., BELMONTE, T., PONCIN-EPAILlARD, F., et al., "Treatment of Hexatriacontane by Ar-O 2 Remote Plasma: Formation of the Active Species", Plasma Processes and Polymers, v. 6, n. S1, pp. S198-S203, Jun. 2009.

[19] BERNARDELLI, E.A., MAFRA, M., MALISKA, A.M., et al., "Influence of neutral and charged species on the plasma degradation of the stearic acid", Materials Research, v. 16, n. 2, pp. 385-391, Apr. 2013.

[20] FARIAS, C.E., BIANCHI, J.C., OLIVEIRA, P.R. de, et al., "Evaluation of sample temperature and applied power on degradation of stearic acid in inductively coupled radio frequency plasma", Materials Research, v. 17, n. 5, pp. 1251-1259, Oct. 2014.

[21] PEARSE, R.W.B.W.B., GAYDON, A.G.A., The Identification of Molecular Spectra, 4th ed. New York: Willey, 1950.

[22] KNOERZER, K., MURPHY, A.B., FRESEWINKEL, M., et al., "Evaluation of methods for determining food surface temperature in the presence of low-pressure cool plasma", Innovative Food Science \& Emerging Technologies, v. 15, n. 1, pp. 23-30, Jul. 2012.

[23] MEISTER, J., BÖHM, G., EICHENTOPF, I.-M., et al., "Simulation of the Substrate Temperature Field for Plasma Assisted Chemical Etching", Plasma Processes and Polymers, v. 6, n. S1, pp. S209-S213, Jun. 2009.

[24] THIRY, D., APARICIO, F.J., LAHA, P., et al., "Surface temperature: A key parameter to control the propanethiol plasma polymer chemistry", Journal of Vacuum Science \& Technology A: Vacuum, Surfaces, and Films, v. 32, n. 5, pp. 50602, Sep. 2014. 
[25] MAFRA, M., BELMONTE, T., PONCIN-EPAILlARD, F., et al., "Role of the Temperature on the Interaction Mechanisms Between Argon-Oxygen Post-Discharge and Hexatriacontane", Plasma Chemistry and Plasma Processing, v. 28, n. 4, pp. 495-509, Jun. 2008.

[26] SCHEER, a M., MOZEJKO, P., GALLUP, G. a, et al., "Total dissociative electron attachment cross sections of selected amino acids", The Journal of chemical physics, v. 126, n. 17, pp. 174301, May 2007.

[27] OZEN, R., KUS, N.S., "A mild and effective method for the conversion of alkenes into alcohols in subcritical water”, Journal of the Serbian Chemical Society, v. 72, n. 10, pp. 941-944, 2007.

[28] JIN, F., MORIYA, T., ENOMOTO, H., "Oxidation Reaction of High Molecular Weight Carboxylic Acids in Supercritical Water”, Environ. Sci. Technol., v. 37, n. 14, pp. 3220-3231, Jun. 2003.

[29] RATKIEWICZ, A., TRUONG, T.N., "Kinetics of the C-C bond beta scission reactions in alkyl radical reaction class", The journal of physical chemistry. A, v. 116, n. 25, pp. 6643-54, Jun. 2012.

[30] SUlZER, P., ALIZADEH, E., MAURACHER, A., et al., "Detailed dissociative electron attachment studies on the amino acid proline", International Journal of Mass Spectrometry, v. 277, n. 1-3, pp. 274-278, Nov. 2008. 